\title{
Diabetes, Obesity and the Nutrition Transition in the Mercosur
}

\author{
Tatiane Andreazza Lucchese1, Amanda Maia Breis', Karine Rucker¹, Vagner Rosa Bizarro1, \\ Lis Marina Mesquita Araújo', Alessandre Gomes', Mikele Torino Paletti, \\ Ana Luísa Conceição de Jesus ${ }^{1}$, Marcella Garcez Duarte², \\ Denise Rosso Tenório Wanderley Rocha1, Alberto Krayyem Arbex ${ }^{1,3}$ \\ ${ }^{1}$ Division of Endocrinology, IPEMED Medical School (IPEMED), São Paulo, Brazil \\ ${ }^{2}$ Brazilian Association of Nutrology (ABRAN), Catanduva, São Paulo, Brazil \\ ${ }^{3}$ Visiting Scholar, Harvard T. H. Chan School of Public Health, Harvard University, Boston, USA \\ Email: tatiandreazza@gmail.com, albertoarbex@gmail.com
}

Received 13 December 2015; accepted 11 January 2016; published 14 January 2016

Copyright (C) 2016 by authors and Scientific Research Publishing Inc.

This work is licensed under the Creative Commons Attribution International License (CC BY). http://creativecommons.org/licenses/by/4.0/

(c) (i) Open Access

\begin{abstract}
Diabetes and obesity are major health hazards in Latin America nowadays. Their prevalence has steadily increased since the eighties. Today, more than $50 \%$ of the population are overweight, $15 \%$ has obesity and $6 \%$ to $15 \%$ has diabetes. The nutrition transition is a long-term process that brings chronic metabolic diseases as an undesired consequence, whilst ultra processed foods become increasingly part of daily food choices. These changes bring impacts in all fields of daily life, especially in the economic and legal fields - the "Right to Health"-and regarding autonomy of the individual and their choices, when confronted with an ideal of health and well-being. Governments and citizens struggle to propose new pathways and find effective solutions to control both epidemics and solve these issues. This article poses the evolution of diabetes and obesity in the Mercosur, seeking a better understanding of these chronic, non-communicable diseases, and looking for concrete, effective solutions towards health in South America.
\end{abstract}

\section{Keywords}

Obesity, Diabetes, Mercosur, Nutrition Transition, Right to Health, South America

\section{Introduction}

For 30 years now, nutrition transition has been changing the pattern of chronic diseases' prevalence in Latin American countries. Three factors contribute for this change: 1) increasing urbanization; 2) reduced physical ac- 
tivity; 3) changes in nutritional patterns. This article intends to study the current status of obesity and diabetes in the Mercosur ${ }^{1}$ (Brazil, Argentina, Paraguay and Uruguay), and look for a better understanding of this condition and its future perspectives.

The increase of the consumption of processed and ultra-processed foods, which are high in fat, sodium and sugar, is a major cause of metabolic diseases. The consequent decrease on the consumption of traditional foods that compound the original latinamerican diet, which includes rice and beans, fruits and vegetables, contributes for the current situation. Especially in the last decade, overweight and obesity increased in all population groups of this region in South America.

Keeping a healthy diet and regular physical activity is associated with lower levels of chronic diseases, as well as cardiac and cerebrovascular events. The growing prevalence of cardiovascular risk factors such as diabetes, obesity, hypertension, dyslipidemia and a sedentary lifestyle explains a big part of the morbidity and mortality, turning them into a major public health problem in the Mercosur [1].

\section{Nutritional Transition and the Changing Food Patterns in the Mercosur}

The effects of globalization and urbanization on food patterns have influenced dietary choices and lifestyle of the world's population in general [2].

According to Popkin, Sichieri (2003), the "Nutritional Transition" phenomenon refers to changes in the diet structure, associated with economic, social and demographic changes and their impact on populational health [3]. The stage and the speed of this transition differ according to the regions where it develops. The basic feature that has been observed in developing countries, including Mercosur countries, is the increased consumption of saturated fatty acids, sugars and soft drinks at the expense of reduced consumption of complex carbohydrates, fruits and vegetables [4].

Although cereals and grains, beans, rice and leguminous are still the main source of calories in the Mercosur countries, plants, for example, show a clear decrease in their consumption in recent years, along with an increase in the consumption of animal protein (eggs, milk, meat). The calorie intake (kcal/day) showed a slight increase in most of these countries to reach around $3000 \mathrm{kcal} /$ day in Brazil and Argentina, for instance.

One of the factors that contribute to this change in habits is the increased consumption of food outside home. In Brazil, a research found out that this consumption varies from $13 \%$ among the elderly in the South to $51 \%$ of young people in the southeast region of the country (the most developed region), and found that the higher the family income, the more frequent is this consumption outside home. The food groups with the highest percentage of consumption outside home were beverages, fried snacks and baked goods, pizza, soft drinks and sandwiches, both in rural and urban areas [4].

The characteristics and stages of development in the nutritional transition differ among the various Latin American countries [5]. Paraguay, for example, is the only Mercosur member that presents, according to a study of the IEA (Institute of Agricultural Economics), a decrease in the total calorie intake among the four members [6].

In the last 20 years Latin American countries have undergone a fast demographic, epidemiological and nutritional transition; a shift from malnutrition to obesity. Many regional governments still do not understand this change, and keep fighting undernourishment as a priority.

\section{Chronic Diseases and Cardiovascular Risk}

Dietary factors are a leading cause of death in Latin American countries. Increased intake of fats, especially saturated fat in general, is the important and directly related to the increased prevalence of cardiovascular disease and other chronic diseases [5].

A sedentary lifestyle, favored by modern life, is a risk factor as important as improper diet in the etiology of obesity [4] and has a direct relationship with the increasing incidence of type 2 diabetes in adults.

Chronic non-communicable diseases (NCDs) are a major public health problem in the world today, with a high morbidity and mortality. Among these diseases, there are the circulatory system, cancer, diabetes and chronic respiratory disease. Obesity is a major risk factor for these diseases, as well as smoking, unhealthy diets,

\footnotetext{
${ }^{1}$ Only the original members of the Mercosur were included in this study, because they share similar patterns and have already built a common background. Venezuela was included in this group for only 2 years now, and still struggle with international questionings regarding being a representative democracy.
} 
physical inactivity and alcohol consumption [7].

Overweight and obesity have a significant impact on physical and psychosocial health and are closely related to eating habits, among many other key aspects of overweight. Especially hypertension and diabetes make up the group of non-transmissible chronic diseases, both as a disease and a risk factor for other diseases. All of them have had an increase in their prevalences in recent decades. For these reasons, among others, nutrition has become one of the most modifiable determinants of chronic diseases, occupying the place that recently would belong to smoking [8]-[10].

\section{Obesity in the Mercosur}

More than half of all adults in the Mercosur are overweight. Approximately 15\% are obese.

In Brazil, NCDs accounted for $72 \%$ of total mortality in the country in 2007 [11]. It is estimated that overweight and obesity are responsible for 2.8 million deaths each year [12]. In Argentina, only 26\% of the population has a normal body mass index (BMI). The rest of the population is divided into overweight (49\%) and obese (25\%) [9]. These data show that developing countries have experienced a problem of malnutrition / malnourishment for overweight and obesity epidemic [12].

The prevalence of obesity has increased markedly in the world, especially during the last 10 to 15 years, becoming a public health problem [6]. Overweight is related to serious health problems, including breast and colon cancer and especially diabetes and heart disease [13], thus influencing the morbidity and mortality of these populations profile.

The studies confirm the growing magnitude of the obesity problem in children, adolescents, adults and childbearing-age women. As determinants, they identify sedentary lifestyle and consumption of inadequate diets. Above all, they issue a call for a greater diversity of interventions and government support with the implementation of clear measures for preventing and combating obesity. Obesity today is no longer a problem only for the so-called developed countries; rather, it increasingly affects growing portions of the most underprivileged population strata [8].

According to the study "Trends in prevalence of overweight and obesity in adults in 26 Brazilian state capitals and the Federal District from 2006 to 2012”, the prevalence of overweight in adults in the 27 cities monitored by VIGITEL (Surveillance System of Risk and Protective Factors for Chronic Non-Communicable Diseases through Telephone Interviews) increased from 43.2\% (2006) to 51.0\% (2012), with an annual increase rate of $1.37 \%$. Prevalence of obesity increased from $11.6 \%$ to $17.4 \%$, with an annual increase rate of $0.89 \%$. The perspectives of disease's prevalence for next years: increase and epidemic.

Knowing the perspective of the overweight's prevalence (overweight plus obesity) associated or not with diabetes mellitus, as well as the trend of prevalence of this, it is vitally important for the development of public policies to face that.

In this context, within MERCOSUR, Brazil has had a prominent position in fighting excess weight epidemic in the region. Using surveillance actions, with data collected annually from Brazilian Health Ministry by VIGITEL (the Portuguese acronym for Risk and Protective Factors Surveillance for Chronic Diseases by Telephone Interviews), a methodological and scientific system sampling done annually by phone calls, although not the best way, to be subject to multiple biases, shows a satisfactory estimate of the prevalence in the population to so-called risk factors since the year 2006 [14]. The survey reveals that being overweight affects $52.5 \%$ of the adult population in the country, significant growth compared with the 2006 data, when the index was $43 \%$, with an increase of $23 \%$ over the last nine years. Excess weight tends to increase with age. Among young people is $38 \%$ and among people 45 - 64 years old, $61 \%$. The result also indicated the presence of obesity in $17.9 \%$ of the study population, with an increase in prevalence since 2006. However, demonstrating for the past three years, no significant increases.

However, one point stands out, namely the marked increase in the prevalence of obesity in the various population sub-groups in nearly all Latin American countries. Within this context, obesity has taken hold as a nutritional problem associated with a high incidence of cardiovascular diseases, cancer and diabetes, thereby influencing the morbidity and mortality profile of populations [8].

In recent years, despite the accumulation of a certain amount of knowledge concerning the determination and distribution patterns of obesity within the context of the nutritional transition, much remains to be done, especially in the field of prevention and population intervention [8]. 


\section{Diabetes in the Mercosur}

In the economically emerging countries such as in Mercosur, the prevalence of diabetes increased rapidly in the last 30 years [15]. As a result, government vigilance actions and health promotion were built to confront these circumstances, reinforced by the WHO recommendations in this same direction. The complexity of determining factors involved in metabolic diseases is a hindrance towards an effective approach. It takes a collective and multisectorial initiatives, in many spheres of society, to understand and to find effective measures towards diabetes control and prevention.

According to the International Diabetes Federation (IDF), there are around 387 million people in the world with diabetes. Eighty percent of these patients live in developing countries [16]. The growing trend of diabetes is associated with irregular lifestyle habits, such as inadequate diets and an increased sedentary lifestyle. Excess weight is a major risk factor for the development of diabetes [17]. Another contributing factor for this epidemiological information is that populations are living longer, and diabetes is prevalent in elderly people, following a higher life expectancy in the Mercosur populations [3].

In the time span analyzed, approximately 19 million patients with type 2 diabetes in the countries that compose the Mercosur. Brazil has the highest number of diabetic patients, corresponding to 11.6 million, followed by Colombia (2.1 million), Argentina (1.6 million) and Chile (1.6 million). Regarding the prevalence within the age group 20 - 79 years (adults), Argentina has the highest percentage (12.3\%), while Brazil, Colombia and Uruguay stands out with $8.7 \%, 7.2 \%$ and $6.6 \%$, respectively (Table 1 ).

Is it important to outline that the prevalence of diabetes increases with advancing age, as Figure 1 shows, and over the fifth decade of life diabetes represents an important health issue among South American populations.

\section{Lawsuits on Obesity and Diabetes}

A quantitative analysis regarding recent juridical decisions on obesity and diabetes, in the higher courts of Brazil and Argentina, shows a similar pattern of increasing demands on these issues, an important reason for concern.

The uniterm "obesity" was found in 37 decisions of the higher court of Brazil, in 12 decisions of the higher Argentinean Court, and in 36 decisions of various levels of courts in Uruguay (which allows no consultation to decisions regarding only the higher court) [18]-[20]. Paraguay does not have such an online research system available [21].

Regarding “diabetes”, 38 decisions were found in Brazilian Higher Court, 30 decisions in Argentinean Higher Court, and 85 decisions in various court levels in Uruguay.

These results clearly indicate the presence and relevance of these diseases on the juridical system, and a major influence on lawsuits within the Mercosur. When each case is analysed, a trend is found in most decisions regarding demands towards the "Right to Health" in these Mercosur countries, possibly explained because of the historical pattern of negligence towards public health care in Latin America. Most of the claimants request access to medications to treat their health condition, or the right to undergo bariatric surgery or other health procedures. Medical treatments have become increasingly expensive, and therefore individuals seek economic sup-

Table 1. Prevalence of type 2 DM in the Mercosur.

\begin{tabular}{cccc}
\hline Country & Cases in 2014 (n) & Prevalence (adults, \%) \\
\hline Brazil & 11.6 millions & 8.7 \\
Colombia & 2.1 millions & 7.2 \\
Argentina & 1.6 millions & 6.0 \\
Chile & 1.5 millions & 12.3 \\
Peru & 1 million & 6.1 \\
Ecuador & 544,000 & 5.7 \\
Bolivia & 371,100 & 6.3 \\
Paraguay & 243,800 & 6.2 \\
Truguai & 150,000 & 6.1 \\
\hline
\end{tabular}

IDF, 2014. 


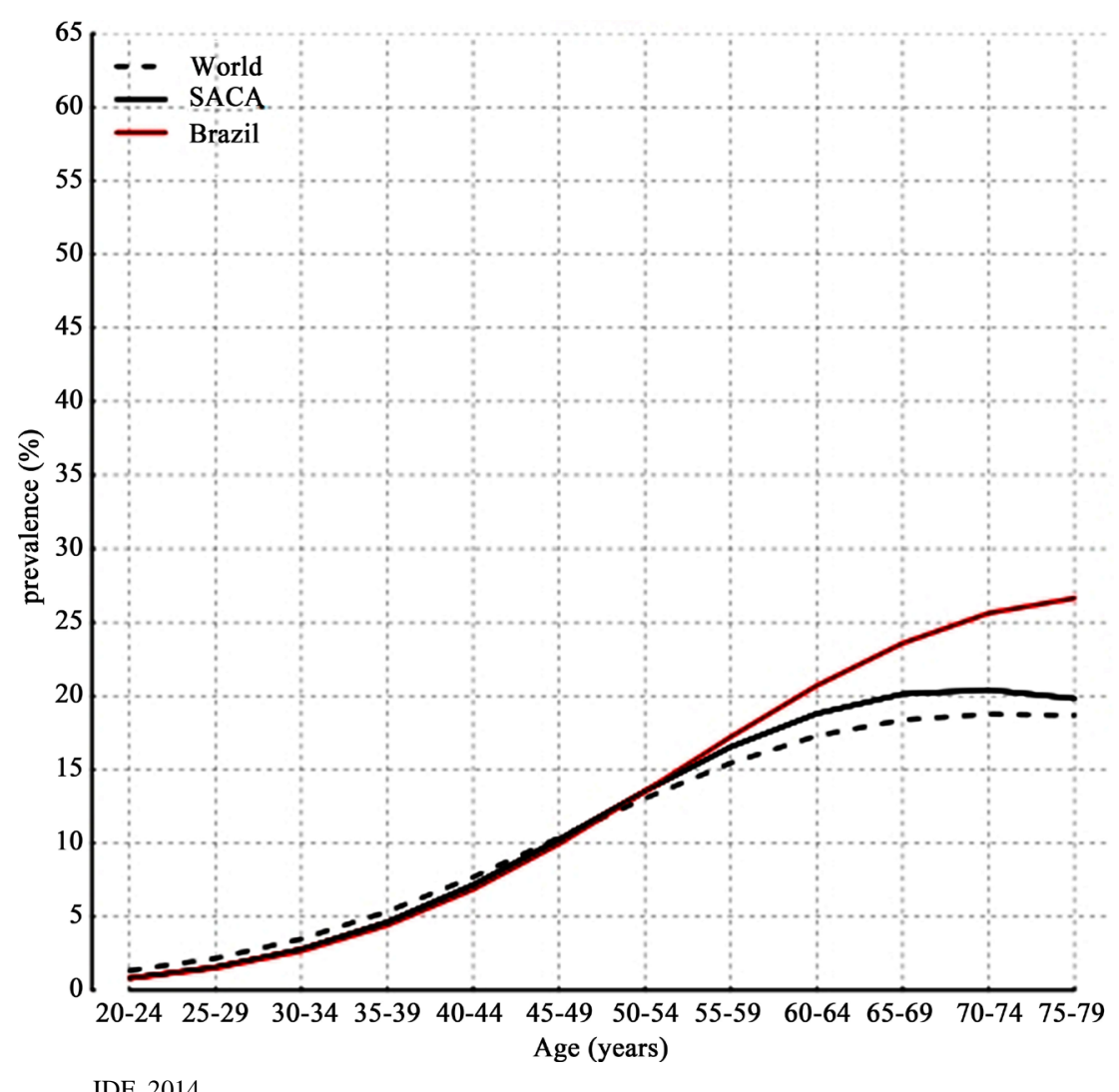

Figure 1. Prevalence of type 2 diabetes, according to age.

port from governments, according to the universal "Right to Health" that states in their Constitutions and in international treaties [22].

\section{The Right to Choose and Government's Role}

Governments face a complex challenge in the control and prevention of diabetes and obesity. Some causal factors associated with NCDs are in part behavioral and depend on individual choices, such as food and drink consumption, thus making government's intervention a complex and arguable task [23].

There are several debates under way regarding who should define an individual's health threshold. Governments decide which are the limits of health and disease, in order to build public health policies and define approaches towards chronic diseases. These (bio) political decisions usually do not take into account the personal right to decide what is best for each citizen and each person [24]. They focus, instead, in planning health prevention and producing health costs' reduction. Public policies regarding obesity and diabetes as very important for nations's public budgets nowadays, because the costs of health are increasing in all countries, and pose a special challenge to Latin American countries, whose budget is extremely limited, along with social and economic priorities [25].

A historical analysis of health reforms lead by governments in the recent decades point out to a pattern of public intervention in the private sphere, regarding health habits, physical activity and food pattern changes. The seven trigger points that justified these initiatives were: social disapproval, medical and scientific discoveries, self-help, blaming those associated with users of these risk factors (e.g. tobacco, alcohol, trans fat), "demonization” of the industry, popular movements and group actions [23].

It is to expect that "biopolitics", regarded as the control of health by the State, are going to be the next frontier of this huge health debate [26]. What are the limits of governments to decide what is healthy of unhealthy, and should an individual follow strict guidelines in order to prevent diseases, leaving own choices with a minor function? Who should decide what is best for a person: a public policy or self-determination? Or should the 
government "nudge" the people to make healthier choices [27] [28]?

Decisions are yet to be reached, and the limits for action will surely be defined. The search for fair answers is under way; not only in Latin America, but all around the world.

\section{Solutions within the Mercosur, and Perspectives for the Near Future}

Efforts to educate populations about the importance of a healthy diet and the establishment of policies for assessing the quality of the food and its nutrients, as well as guidelines and a diversity of actions for access to healthy food, might help to reduce the alarming increase of obesity and chronic diseases, such as diabetes, in the Mercosur.

\subsection{Argentina}

Argentina has introduced public policies for dealing with non transmissible chronic diseases. It conducted in 2014 the third edition of ENFR (the Spanish acronym for "National Survey of Risk Factors" for non transmissible Diseases), also developed by phone calls and with national coverage [29].

Through this survey it was observed the prevalence of excess weight was around $60 \%$ of the Argentine population, and $20.8 \%$ were obese. This represented an increase of $42.5 \%$ in the prevalence of obesity when compared to 2005, and a lower increase over the numbers of 2009. A higher prevalence of obesity among Argentinean women was reported.

These data provided support for the creation and improvement of public policies on chronic disease confrontation. The Food Guide has been updated and adjusted to the Argentinean Population, and enhanced the Clinical Practice Guidelines of diabetes and obesity, inserted in context of more comprehensive programs for the control of diabetes and obesity [30].

The Argentinean government went further and launched the campaign "Argentina 2014 Trans Fat Free” eliminating trans fat from processed foods intended for human consumption, aiming to promote a high impact on chronic diseases, providing better nutrition and achieving a healthy lifestyle in the population. Underlying, through the project "Protection of Vulnerable Population Against Non Communicable Chronic Diseases" assured resources to states to improve public health services, including high-quality care and expand the capacity of primary care centers. Also implemented the "National Program of the fight against sedentary lifestyle" to increase knowledge, awareness and appreciation of the benefits of physical activity to humans. Promote the development of skills for society to incorporate an active lifestyle and help people overcome their difficulties.

Among the national targets of the Plan for combating chronic non transmissible diseases in Brazil (20112022), obesity goals are to reduce the prevalence of obesity in children from 5 to 9 years of age, from $16.6 \%$ (2008) to $8.0 \%$ (2022) in males and from $11.8 \%$ (2008) to 5.1\% in females; reduce obesity in adolescents from 10 to 19 years old, male gender from $5.9 \%$ (2008) to $3.2 \%$ (2022) and in female gender from $4.0 \%$ (2008) to $2.7 \%$ (2022); stop the growth of obesity in adults, stabilising for the next ten years the prevalence of 2008: $48.1 \%$ of overweight and $15 \%$ of obesity, which are already high levels of excess weight; to increase the prevalence of physical activity during leisure time; increase the consumption of fruits and vegetables; reduce the average salt intake to 5 grams (the means was of 10 grams in 2010) [31].

Argentina has a national programme for the prevention and control of diabetes ("PRONADIA"). This Programme attempts to engage and commit the provinces to develop and implement subnational programmes for disease control and treatment. Its main aim is "to improve the quality and life expectancy of people with diabetes, prevent or decrease chronic complications of this disease and ensure the consequent decline of direct and indirect costs [3].

In order to achieve these aims it promotes the active implementation of a prevention and control programme that prioritises appropriate interventions on hyperglycaemia and the associated cardiovascular risk factors (CVRFs) and its chronic complications. Its role is to coordinate and provide technical support for the programming and implementation of provincial programmes. Currently all the provinces have either adopted or adapted the PRONADIA principles, being supported with their own budget (federal health care system).

Additionally, the National Health Ministry has also developed guidelines for the prevention, diagnosis and diabetes treatment targets, based on international guidelines and with the participation of different academic, scientific and health care organisations.

In 2010, PRONADIA tried to widely implement the QUALIDIAB registry through the provincial diabetes 
programmes, to assess and follow up objectively the quality of care provided to people with diabetes and other CVRFs. This system has introduced small changes in the original QUALIDIAB data record in order to use a single data collection form for all the CVRFs. This new form, that includes the impaired glucose tolerance and impaired fasting glucose conditions, is part of a WHO programme to identify people with CVRFs and their treatment. The data recording sheet includes indicators on processes, clinical and metabolic outcomes, drug consumption, hospitalisation events and chronic complications. There is a programme for the free provision of drugs at national level (REMEDIAR); it supplies metformin, glibenclamide and human insulin to publicly insured diabetic patients through primary care units and public hospitals all over the country [3].

Additionally, the "Superintendencia de Servicios de Salud" is the national institution that assess the degree of coverage of care and drug treatment by all institutions of the social security system as well as prepaid ones, as established in the PRONADIA, thus they have to cover $100 \%$ of the cost of insulin and traditional oral hypoglycaemic agents as well as up to 300 strips for self-monitoring of blood glucose/year. The free provision of new drugs and insulin analogues is not automatically granted and their coverage/provision is under an audit system, i.e. physicians have to demonstrate in a written form, how essential is its usage [3].

\subsection{Brazil}

In 2011, Brazil created the Fight Plan of Chronic Non Transmissible Diseases by defining and prioritizing actions and investments needed to prepare the country to face this reality in the next 10 years (2011-2022). The Plan has three main guidelines: 1) surveillance, information, evaluation and monitoring; 2) health promotion; 3) comprehensive care [11].

The surveillance is to assess and monitor risk factors, access to essential health services and drug and monitor morbidity and mortality, outlining in this way, prevention and health promotion policies [32]. As for health promotion, actions have been defined for the encouragement of physical activity (outdoor gyms, implementation of healthy habits in schools, construction of squares, communication campaigns that encourages physical activity); encouraging healthy eating, offering healthy food in schools, agreements with industry to reduce the salt and sugar, reducing the prices of healthy foods. Already comprehensive care includes training activities and telemedicine, free medication, aimed at strengthening and at the responsiveness of the Unified Health System [11].

In order to encourage civil society to deal with food components, nutrition and healthy consumption, the government developed in partnership with the University of Brasília, the "Virtual Network Ideas on the Table". On the site experiences of Food and Nutrition Education are shared in the country and broadcast technical content, conceptual and methodological references.

The Brazilian Ministry of Health launched in 2014 a new Food Guide [15]. The update of the publication reports that care and ways to achieve a healthy, tasty and balanced food consumption. Rather than working with food groups and recommended servings, it indicates that the feeding is based on fresh food (fruit, meat, vegetables) and minimally processed foods (rice, beans and dry fruits), and avoid ultra-processed foods, such as instant noodles, snacks and soft drinks. The intention of the Guide is to promote health and good diet, combating malnutrition in sharp decline across the country, and preventing diseases on the rise, such as obesity, diabetes and other chronic diseases, for instance, stroke, myocardial infarction and cancer. In addition to guidance on what type of diet, provides information on how to eat and prepare the meal, and suggestions to face daily obstacles to maintaining a healthy eating pattern [12] [15].

According to the Balance of the Shares of National Food Security and Nutrition Plan, the Food and Nutrition Education Actions are among the main strategies to promote adequate and healthy food established by the National Policy for Food and Nutrition Security. The document released by the Interministerial Chamber on Food and Nutrition Security (“Caisan”) in 2014, lists a number of educational activities in search of improvement in the diet, appreciation of the Brazilian regional food culture, reducing food waste, and promoting sustainable consumption and healthy eating, resulting in the prevention and control of non-communicable diseases and nutritional deficiencies resulting from inadequate nutrition.

\subsection{Uruguay}

Since 2012, the Uruguayan government implemented the program FOOD REVOLUTION IN SCHOOL CANTINA, banning the sale of soft drinks, snacks, chocolates and other foods considered inappropriate to health. Entered the sale of healthy food such as $100 \%$ natural juices, fruits and cereals. Concurrently began a 
campaign of good eating habits through advertising in various media and delivery of textbooks to all students. This year the National Strategy for Health Promotion (PREVENINDO) together with the Ministry of Public Health (MPH) created the cooperative fund for health promotion projects (FUSI), to encourage community health promotion projects and prevention of chronic diseases.

In 2013 Uruguay approved the "Ley de Alimentación Saludable de Niños y Jóvenes" (Law for a better eating of children and young people), law nr. 19140, restricting sellings of the so-called "junk food" in Uruguayan schools. Yet considered insufficient to deal with this major hazard, it is expected by authorities to stimulate healthier food practices among children in Uruguay [33].

\subsection{Paraguay}

Following the same model, Paraguay established the Program of the "Healthy School Cantina" (Cantina Escolar Saludable), according to the government's resolution 16,624 as of 2013. The Paraguayan authorities seek to protect the health of students through a balanced diet. They conduct purchases of food directly from the country's Family Agriculture, and simultaneously distribute booklets to people with dietary guidelines. The goal is not only to spread and publicize current data regarding health foods to educators, but also to train cook specialists and include the families of the students in a broader debate regarding food and health [34].

\subsection{Mercosur}

Many goals of Mercosur countries seek similar global targets, regarding the reduction and control of overweight, obesity and diabetes prevalence, a decrease in risks factors and health promotion policies. With this set of indicators being evaluated in a similar way in the world, it will be possible to perform international assessments of specific situations and trends of NCDs over time, thus assisting in monitoring the situation in each country, and supporting public policies in countries of the same region—or same development category [35].

Other national system responses are national policies that limit satured fatty acids and eliminate partially hydrogenated vegetable oils, in addition to policies to reduce the impact on children of marketing of foods and non-alcoholic drinks in saturated fats, fatty acids and trans fats, free sugars or salt [36].

Unfortunately, initiatives are restricted to each specific country of the Mercosur, and no common or joint health plan regarding NCDs has been approved so far. This could be an effective way of controlling and understanding these chronic diseases.

\section{Conclusions}

NCDs pose a major challenge for the populations of the Mercosur nowadays, because of their high prevalence and associated comorbidities. Obesity and diabetes are health conditions that affect individuals, governments and influence many aspects of health and life.

In public health, evidences suggest that public policies are essential to control obesity, diabetes and associated disorders. However, habit changes resulting from population policies are rarely effective, and the results depend on many variables. The campaign against smoking, which also involved public agencies and other sectors of society, through incentives, could be an example to be followed.

Several studies showed that healthy dietary interventions focusing in children, since pre-school, may significantly increase the consumption of fruit and vegetables, as well as add knowledge related to good nutrition, which become lifelong tools for better food choices. Children nowadays learn about food in schools, and receive excess information through the media and communication channels, which might be a benefit or a risk.

There are several points that must be analyzed on an approach towards a better health of individuals. Public health policies should focus in achieving adequate results, whilst preserving an individual's autonomy and still looking for effective measures to control these both epidemics. These goals have not been reached so far.

We live in a time of food awareness, in which joint actions between states and citizens should be stimulated. Public and private health initiatives, especially those aimed at children, could be able to improve the current scenario in the near future.

\section{Acknowledgements}

We would like to thank CAPES for supporting clinical research in Brazil. 
We thank the PPGBIOS Post graduate research Group, FIOCRUZ, Professor Dr. Murilo Mariano Villaça and Professor Dr. Maria Clara Marques Dias for their continuous feedback, guidance and comprehension regarding research initiatives in Latin America and elsewhere.

\section{Conflicts of Interest}

The authors show no conflicts of interest.

\section{References}

[1] Schmidt, M.I., Duncan, B.B., Silva, G.A., Menezes, A.M., Monteiro, C.A., Barreto, S.M., Chor, D. and Menezes, P.R. (2011) Chronic Non-Communicable Diseases in Brazil: Burden and Current Challenges. Lancet, 377, 1949-1961. http://dx.doi.org/10.1016/S0140-6736(11)60135-9

[2] Hawkes, C. (2006) Uneven Dietary Development: Linking the Policies and Process of Globalization with the Nutrition Transition, Obesity and Diet-Related Chronic Diseases. Globalization and Health, 2, 4. http://dx.doi.org/10.1186/1744-8603-2-4

[3] Tardido, A.P. and Falcão, M.C. (2006) O impacto da modernização na transição nutricional e obesidade. Revista Brasileira de Nutrição Clínica, 21, 117-124.

[4] Bezerra, N.I., Souza, A.M., Pereira, R.A., et al. (2013) Consumo de alimentos fora de casa no Brasil. Revista de Saúde Pública, 47, 200S. http://dx.doi.org/10.1590/S0034-89102013000700006

[5] Sartorilli, D.S. and Franco, L.J. (1906) Tendências do DM no Brasil: O papel da transição nutricional. Cadernos Brasileiros de Saúde Pública, 19, S29-S36. http://dx.doi.org/10.1590/S0102-311X2003000700004

[6] Prentice, A.M. and Jebb, S.A. (1995) Obesity and Britain: Gluttony or Sloth? BMJ, 311, 437-439. http://dx.doi.org/10.1136/bmj.311.7002.437

[7] World Health Organization (2009) Global Health Risks: Mortality and Burden of Disease Attributable to Selected Major risks. World Health Organization, Geneva.

[8] Alves, L.J. (2009) Transição epidemiológica nutricional em crianças e adolescentes argentinos de áreas carentes. Revista Paulista de Pediatria, 27, 124-126. http://www.scielo.br/scielo.php?script=sci arttext\&pid=S0103-05822009000200001\&lng=en http://dx.doi.org/10.1590/S0103-05822009000200001

[9] Ministério da Saúde, Brasil (2006) Cadernos de Atenção Básica—No. 12. Séria A. Normas e Manuais Técnicos. Obesidade. http://www.saude.gov.br/bvs

[10] Departamento de Atenção Básica, Secretaria de Atenção à Saúde, Ministério da Saúde, Brasil (2013) Diretrizes para o cuidado das pessoas com doenças crônicas nas Redes de Atenção à Saúde e nas linhas de cuidado prioritárias. http://www.saude.gov.br/bvs

[11] Malta, D.C., et al. (2011) Apresentação do Plano de Ações Estratégicas para o Enfrentamento das Doenças Crônicas Não Transmissíveis no Brasil, 2011-2022. Epidemiologia e Serviços de Saúde, 20, 425-438.

[12] World Health Organization (2005) Preventing Chronic Diseases: A Vital Investment. Organização Pan-Americana da Saúde, Brasília.

[13] Pasca, A.J., et al. (2003) Obesidad y prevención secundaria em la República Argentina. Revista de la Federación Argentina de Cardiología, 32, 44-49.

[14] Brazil. Ministry of Health (2014) VIGITEL 2014—Vigilância de Fatores de Risco e Proteção para Doenças Crônicas por Inquérito Telefônico. http://portalsaude.saude.gov.br/images/pdf/2015/abril/15/PPT-Vigitel-2014-.pdf

[15] Brazil. Ministry of Health (2014) Secretaria de Atenção à Saúde. Departamento de Atenção Básica. Dietary Guidelines for the Brazilian Population. 2nd Edition.

[16] International Diabetes Federation (2014) IDF Diabetes Atlas. IDF, Brussels. https://www.idf.org/idf-atlas/scientific-papers

[17] World Health Organization (2002) The World Health Organization Report 2002: Reducing Risks, Promoting Healthy Life. WHO, Geneve.

[18] Argentina. Corte Suprema de Justicia de la Nación. http://www.csjn.gov.ar/

[19] Brazil. Supremo Tribunal de Justiça. http://www.stf.jus.br/portal/principal/principal.asp

[20] Uruguay. Suprema Corte de Justicia.

http://www.poderjudicial.gub.uy/institucional/poder-judicial/suprema-corte-de-justicia.html

[21] Paraguay. Corte Suprema de Justicia. http://www.pj.gov.py/ 
[22] Organization of American States (1969) American Human Rights Convention. Pact of San José, Costa Rica. http://www.oas.org/dil/treaties_B-32_American_Convention_on_Human_Rights.htm

[23] Kersh, R. and Morone, J. (2002) The Politics of Obesity: Seven Steps to Government Action. Health Affairs, 21, 142-153. http://dx.doi.org/10.1377/hlthaff.21.6.142

[24] Foucault, M. (1997) Il fautdéfendre la societé [We Must Defend Society]. Brazilian Edition, Martins Fontes, Ed., 382 p.

[25] Sichieri, R., Nascimento, S. and Coutinho, W. (2007) The Burden of Hospitalization Due to Overweight and Obesity in Brazil. Cadernos de Saúde Pública, 23, 1721-1727. http://dx.doi.org/10.1590/S0102-311X2007000700025

[26] Esposito, R. (2008) Bíos. Biopolitics and Phylosophy. University of Minnesota Press, Minneapolis/London, 230 p.

[27] Palma, A., Ferreira, N.T., Vilaça, M.M. and Assis, M. (2015) Conflicts of Interest in the "War” against Obesity: Is It Possible Serve Two Masters? Saúde e Sociedade, 23, 1262-1274. http://dx.doi.org/10.1590/S0104-12902014000400012

[28] Thaler, R.H. and Sunstein, C.R. (2008) Nudge. Improving Decisions about Health, Wealth and Happiness. Penguin Books, London, 312 p.

[29] Argentina. Ministério de la Salud (2014) Direção de promoção da saúde e controle de doenças não transmissíveis. ENFR 2014-Encuesta Nacional de Fatores de Riesgo para doenças não transmissíveis. http://www.bvs.org.ar/pdf/enfr2014.pdf

[30] Argentina. Ministerio de la Salud. Direción de Promocion de la Salud y control de Enfermedades no Transmisibles. http://www.msal.gob.ar/index.php/component/content/article/48-temas-de-salud-de-la-a-a-la-z/91-diabetes

[31] Malta, D.C. and Silva, J.R. (2013) O Plano de Ações Estratégicas para o Enfrentamento das Doenças Crônicas Não Transmissíveis no Brasil e a definição das metas globais para o enfrentamento dessas doenças até 2025: Uma revisão. Epidemiologia e Serviços de Saúde, 22, 151-164. http://dx.doi.org/10.5123/s1679-49742013000100016

[32] Scherer, P.T. and Santos, A.M. (2011) A contribuição das políticas públicas no enfrentamento a obesidade no Brasil. Anais da V Jornada Internacional de Políticas Públicas, UFMA, São Luís, 23-26 August 2011, 1755-1762.

[33] Uruguay. Law 19140. Ley de Alimentación de Uruguay. http://es.consumersinternational.org/media/1405496/ley_alimentaci\%C3\%B3n-uruguay-19140.pdf

[34] Paraguay. Ministry of Education and Culture. Cantinas Saludables, un espacio para cuidar la salud. http://www.mec.gov.py/cms_v2/entradas/295243-cantinas-saludables-un-espacio-para-cuidar-la-salud

[35] Bazzano, L.A., Serdula, M.K. and Liu, S. (2003) Dietary Intake of Fruits and Vegetables and Risk of Cardiovascular Disease. Current Atherosclerosis Report, 5, 492-499. http://dx.doi.org/10.1007/s11883-003-0040-z

[36] Reis, C.E.G., Vasconcelos, I.A.L. and Barros, J.F.N. (2011) Políticas públicas de nutrição para o controle da obesidade infantil. Revista Paulista de Pediatria, 29, 625-633. 